\title{
Proximity, knowledge transfer, and innovation in technology-based mergers and acquisitions
}

\author{
Prescott C. Ensign \\ Schlegel Centre for Entrepreneurship, \\ School of Business and Economics, \\ Wilfrid Laurier University, \\ Waterloo, Ontario, N2L 3C5, Canada \\ E-mail: ensign@wlu.ca
}

\section{Chen-Dong Lin}

Human Resources Branch, Canada Revenue Agency, Ottawa, Ontario, K1P 5N2, Canada

E-mail: chen.lin@cra-arc.gc.ca

\section{Samia Chreim and Ajax Persaud*}

Telfer School of Management, University of Ottawa,

Ottawa, Ontario, K1N 6N5, Canada

E-mail: chreim@telfer.uOttawa.ca

E-mail: ajax@telfer.uOttawa.ca

*Corresponding author

\begin{abstract}
This paper presents the findings from a qualitative study on the extent to which three dimensions of proximity - geographic, cognitive, and organisational - impact knowledge transfer and innovation post-merger and acquisition (M\&A). Findings show that the elements of proximity substantially influence both knowledge transfer and innovation although the nature of the impact varies and is influenced by the type of management interventions or lack thereof post-M\&A.
\end{abstract}

Keywords: proximity; knowledge transfer; mergers and acquisitions; M\&A; technology management; innovation; post-M\&A.

Reference to this paper should be made as follows: Ensign, P.C., Lin, C-D., Chreim, S. and Persaud, A. (2014) 'Proximity, knowledge transfer, and innovation in technology-based mergers and acquisitions', Int. J. Technology Management, Vol. 66, No. 1, pp.1-31.

Biographical notes: Prescott C. Ensign is the Dobson Professor of Innovation and Entrepreneurship in the School of Business and Economics at Wilfrid Laurier University. His research has focused on innovation and technology development. His research has also examined the strategy and structure of enterprises as they internationalise. Recently, he has investigated entrepreneurship in remote locations as well as economic development and change in emerging markets. 
Chen-Dong Lin is currently with the Canada Revenue Agency, prior to that he held a position at the Industrial Research Assistance Program, National Research Council of Canada. He completed his MSc in Innovation Management and Entrepreneurship in the Telfer School of Management at the University of Ottawa where he held research and teaching assistantships and was awarded a Joseph-Armand Bombardier Graduate Scholarship from the Social Sciences and Humanities Research Council of Canada. He is also a graduate of the Rotterdam School of Management at Erasmus University located in the Netherlands.

Samia Chreim is an Associate Professor in the Telfer School of Management at the University of Ottawa. Her research interests include the areas of mergers and acquisitions, cross-organisational collaborations, and change management. She has studied these topics in the fields of healthcare, financial services, engineering and information technology. Her most recent research attends to the notion of boundaries at different levels of analysis.

Ajax Persaud is an Associate Professor in the Telfer School of Management at the University of Ottawa. His research focuses on the commercialisation of new technologies, R\&D and innovation management, new product development, technology adoption, and e-business. He has received a number of nominations and awards for teaching and research excellence. He has provided management consulting services to small and medium companies and community organisations in Canada and the Caribbean. He has also delivered executive education courses in innovation management, marketing, and e-business to executives of small, medium, and large multinational corporations in Canada, the Caribbean and Europe.

\section{Introduction}

Mergers and acquisitions (M\&A) have become an increasingly important means to acquire necessary knowledge resources to enhance firms' innovative capabilities (Ranft and Lord, 2002). There are strong arguments suggesting a positive relationship between M\&A and innovative performance. However, empirical evidence indicates a mixed impact of M\&A on firm innovation. For example, M\&A is cited to have a positive impact on innovation based on case study evidence of Cisco Systems (Ferrary, 2003) and Johnson \& Johnson (Barrett, 2002). On the other hand, researchers such as Hagedoorn and Duysters (2000), Hitt et al. (1991) and Man and Duysters (2005) find a negative relationship between M\&A and innovative performance. Prabhu et al. (2005) thus raise an interesting question: Why does M\&A activity work for some, but not for others? One explanation for the equivocal findings is that current research tends to be based on aggregated data - including M\&A activity across different industries and settings - and as a result, positive impacts may be cancelled out by negative ones (Prabhu et al., 2005). Given the lack of clarity, further scholarly investigation is required to identify factors that contribute to post-M\&A performance (King et al., 2004) and to better understand knowledge transfer and innovation following a merger or an acquisition (Hagedoorn and Duysters, 2000).

Technology M\&A has a unique potential to yield superior innovative performance by combining leading-edge technological knowledge found in two companies (Ahuja and Katila, 2001). Early work by Arrow (1969) and Kuznets (1966) has shown that 
knowledge flow is positively associated with innovative performance. But transferring knowledge, especially tacit knowledge, is not easy. Proximity between firms plays a big role in the process of knowledge transfer (Cantwell and Zhang, 2011); however, the impact of proximity has yet to be investigated in-depth in an M\&A setting.

Proximity, in the context of M\&A, refers to the similarity in various aspects such as location, knowledge base, practice, and culture, between two firms involved in M\&A. Geographic proximity has been suggested to have an impact on knowledge transfer within a single organisation (Zander and Kogut, 1995) and between industrial organisations (Ambos and Ambos, 2009; Jasimuddin, 2007). However, there are different dimensions to proximity - such as geographic, cognitive and organisational - as Boschma (2005) has argued. Our understanding of how these different dimensions affect knowledge transfer is incomplete. This study initiates research on this topic in the context of technology-based firms that have engaged in merger or acquisition.

Furthermore, the role of management in knowledge transfer and value creation is well recognised, though not entirely understood. It is posited that management can determine how firms are integrated, which can influence the success of knowledge transfer (Hitt et al., 1991; Haspeslagh and Jemison, 1991). Management can put in place measures to retain key employees so the acquiring firm's knowledge is preserved and transferred (Ranft, 2006; Ranft and Lord, 2002). Managers may also help shape the conditions under which knowledge transfer takes place. When proximity dimensions exert a negative influence on knowledge transfer and innovation, such as alienating cultural practices (Brannen and Peterson, 2009), management can intervene to mitigate this impact.

Given the above, the principal objective of this study is to understand knowledge transfer and its impact on innovation in technology-based M\&A. Specifically, we examine how various proximity dimensions and management interventions influence knowledge transfer and innovation in post-M\&A technology-based companies.

\section{Conceptual overview}

Generally, M\&A performance is evaluated using accounting-based metrics, such as changes in return on equity, return on assets, profitability ratios, market share, patent counts or change in patent authorship (Ahuja and Katila, 2001; Puranam and Srikanth, 2007). There is a dearth of research on M\&A performance in terms of knowledge transfer and innovation.

M\&As enable firms to acquire new technological assets and knowledge quickly (Ranft and Lord, 2000). However, to leverage the knowledge acquired, it must be identified, shared and disseminated. Empirical results on the impact of M\&A on innovative performance are mixed, with some studies reporting no impact, while others reporting some impact (Man and Duysters, 2005; Jensen, 1988). Prabhu et al. (2005) show that M\&As might work well for firms with deep internal knowledge that are seeking external innovation sources because they are better positioned to exploit external knowledge. Depth is defined as "the amount of within-field knowledge possessed by the acquiring firm" [Prabhu et al., (2005), p.115]. Firms with moderate similarity in knowledge bases are more likely to experience positive innovative performance post-M\&A (Ahuja and Katila, 2001; Cloodt et al., 2006; Hagedoorn and Duysters, 2000). Dissimilar knowledge bases would make it harder for firms to integrate their 
technological assets, whereas too much similarity could reduce knowledge synergies and result in fewer knowledge combinations.

\section{Proximity and management intervention}

Knowledge transfer is a challenging part of M\&A activity due to the tacitness of technological knowledge, which may be compounded by a lack of proximity between firms (Cantwell and Zhang, 2011). Proximity in the context of M\&A refers to the similarity in such areas as location, culture, and knowledge base between the two firms involved in the M\&A. This study examines three dimensions of proximity: geographic, cognitive, and organisational (Boschma, 2005). Geographic proximity is the physical closeness, either in the relative or absolute sense, between firms. Cognitive proximity refers to the extent to which firms share the same reference and knowledge. Organisational proximity is the extent to which firms share organisational arrangements, such as hierarchy, routine, and rules.

\subsection{Geographic proximity}

Physical closeness between firms provides the possibility for participants to have greater social interaction, which is crucial for transferring tacit knowledge. Cairncross (1997) argued that with current information and communications technology (ICT) and faster transportation modes, distance has died or is irrelevant. However, Desrochers (2001) and Rallet and Torre (1999) disagreed, arguing that distance still matters and close proximity remains the best way to ensure effective communication regardless of modern communication channels and transportation. Rallet and Torre (1999) claimed that the use of ICT could facilitate the transfer of technological knowledge, but that it is impossible to completely eliminate barriers due to geographic distance. Desrochers (2001) cited the importance of technology clusters as an indication of the importance of physical proximity for knowledge transfer and innovation.

\subsection{Cognitive proximity}

Complementarity in technological knowledge and capabilities is important in determining cognitive proximity. Perez and Soete (1988) argued that firms need to have some shared knowledge in order to understand the technological capabilities of partners. Insufficient cognitive proximity could lead to an inability to communicate and understand new knowledge. Too much shared common knowledge, however, reduces learning potential, e.g., limits sources of novelty, and causes a competence trap where a firm no longer develops necessary technological assets that conform to market developments (Man and Duysters, 2005). Chaudhuri (2004) found that technical incompatibility slows down product development while Breschi et al. (2003) suggested that firms develop new technologies related to their existing knowledge bases faster. It seems that a moderate level of similarity between two firms' knowledge bases is positively related to innovation (Ahuja and Katila, 2001; Cloodt et al., 2006; Man and Duyster, 2005; Prabhu et al., 2005). 


\subsection{Organisational proximity}

Organisational proximity consists of cultural and structural proximity. Cultural proximity includes elements such as language, established practices and rules, and interactions between individuals and groups (Berends et al. 2011). Structural proximity pertains to how firms are regulated at the macro level, such as structure, systems, hierarchy, and power. Boschma (2005) and Blanc and Sierra (1999) assert that organisational proximity provides stable conditions and a consistent environment, which in turn enhances trust, facilitates coordination, and promotes knowledge transfer. Too little organisational proximity could cause a lack of trust and commitment, miscommunication, goal misalignment and cultural conflicts. As a consequence, knowledge transfer could be undermined. In M\&A studies, the most closely aligned concept to organisational proximity is organisational fit, which refers to the level of compatibility in management styles and organisational systems between the acquiring and the acquired firms (Datta, 1991). Organisational fit is considered a key determinant of post-M\&A integration (Jemison and Sitkin, 1986). Uncertainty and confusion are reduced when firms share similarity in organisational arrangements (Hacklin et al., 2010).

Lack of cultural proximity can lead to cultural clash, which is a significant post-M\&A integration problem. Cultural similarity eases integration (Capron, 1999) and enhances performance (Jemison and Sitkin, 1986). Similarly, structural differences between firms might be an obstacle to integration (James et al., 1998). For example, it would be easier for firms that have rigid hierarchical structures to work with other hierarchical firms than with flexible organisations, such as in the case of biotech and pharmaceuticals (Schweizer, 2005).

\subsection{Management intervention}

Research shows that post-M\&A integration is key to M\&A success or failure (Bannert and Tschirky, 2004; Puranam and Srikanth, 2007). Management can intervene when proximity dimensions such as alienating cultural practices (Brannen and Peterson, 2009) impact knowledge transfer and innovation negatively. Ranft and Lord (2000, 2002) emphasise the importance of management of human capital in the transfer of knowledge in technology M\&A settings. Poorly managed M\&A often result in the loss of key employees, and hence the loss of their knowledge and skills, which are critical in post-M\&A innovative performance. Puranam and Srikanth (2007) found that when the acquiring firm intends to leverage the target's existing knowledge, the acquiring firm should try to integrate the target firm into its organisational structure. But if the acquirer intends to leverage the target's capacity to innovate, then a structural integration - which is associated with a loss of autonomy - would negatively impact the innovation outcome, due to the likelihood that highly talented employees may become de-motivated and eventually leave the firm. They argue that if the acquiring firm wishes to keep the acquired firm's innovative capabilities, it should leave it autonomous. Thus, the relevant question is not whether M\&A is good or bad for knowledge transfer and innovation, but what factors influence the outcome.

Given the above overview, we asked two central questions: 
1 How do various dimensions of proximity influence knowledge transfer and innovation?

2 How do management interventions help resolve difficulties associated with proximity factors and facilitate integration and knowledge transfer?

This study looks at innovative performance on the basis of change in incremental and radical innovation. Incremental innovation involves improvement of an existing product or process by exploiting existing technological knowledge and capabilities within a firm (Leifer et al., 2000). Radical innovation involves development of a new product or process to transform the marketplace by exploring new technological opportunities [Leifer et al., (2000), p.5].

\section{Research design and method}

A qualitative research design is deemed appropriate given the complex setting of M\&A. Qualitative research allows researchers to gain insights on how the phenomenon takes place and to determine factors that have a significant influence on the outcome (Miles and Huberman, 1994; Creswell, 2007). Multiple case studies are employed in this study since they permit comparison across the cases (Eisenhardt and Graebner, 2007). The cases met the following predetermined criteria:

1 both the acquired and acquiring firms had to be technology-based firms

2 companies in the selected M\&A cases had to have the intention to integrate and to

have taken significant steps towards integration.

Contacts were sought by phone, e-mail, and through the researchers' professional networks to recruit the identified firms to participate. The study included three M\&A cases, where respondents from both the acquiring and acquired companies were interviewed. Altogether, 13 executives - five from the acquiring firms and eight from the acquired firms - who were knowledgeable about the M\&A deals were interviewed. Interviewees include CEOs, executive managers, integration managers, product managers, $R \& D$ staff, and senior training specialists. The inclusion of participants from each side fostered the understanding of different perspectives on each M\&A. Tellis (1997) noted that this approach is especially important to case studies, which are 'multi-perspectival analyses' that include views from several relevant actors involved in the phenomenon.

The cases involved three Canadian technology-based firms operating in the information and communication technology sector. All had an international component as they were either acquired by or merged with a foreign company. Table 1 provides an overview of the cases in terms of M\&A status, motive, industry, size, and year of deal (pseudonyms are used to conceal the companies' identities). As shown in Table 1, the deals were made for two key reasons, namely, market expansion and the acquisition of technological knowledge and capabilities. The three deals involved fairly large companies but one of the acquiring companies, GiantSoft, was a significantly larger, global corporation. 
Table 1 Case descriptions

\begin{tabular}{|c|c|c|c|c|c|}
\hline Pseudonyms & M\&A type & $M \& A$ motive & Industry & Employee base & Year \\
\hline $\begin{array}{l}\text { Canadian Cansoft } \\
\text { acquired by US } \\
\text { GiantSoft }\end{array}$ & Acquisition & $\begin{array}{l}\text { Acquire knowledge } \\
\text { and capabilities }\end{array}$ & $\begin{array}{l}\text { Computer } \\
\text { software }\end{array}$ & $\begin{array}{l}\text { Acquirer: } 100,000 \\
\text { Acquiree: } 5,000\end{array}$ & 2007 \\
\hline $\begin{array}{l}\text { Canadian } \\
\text { FutureTech } \\
\text { acquired by UK } \\
\text { BrightTech }\end{array}$ & Acquisition & $\begin{array}{l}\text { Market expansion, } \\
\text { acquire knowledge } \\
\text { and capabilities }\end{array}$ & Telecom & $\begin{array}{l}\text { Acquirer: } 1,000 \\
\text { Acquiree: } 1,500\end{array}$ & 2002 \\
\hline $\begin{array}{l}\text { Canadian MajCom } \\
\text { merged with US } \\
\text { NextCom }\end{array}$ & Merger & Market expansion & Telecom & $\begin{array}{l}\text { MajCom: } 1,500 \\
\text { NextCom: } 2,000\end{array}$ & 2007 \\
\hline
\end{tabular}

An interview protocol was used to guide the individual interviews with participants. Three interviews were conducted by two members of the research team jointly, and the remaining interviews were conducted by one member. The interviews were semi-structured to provide room for probing (Patton, 2002). The interview protocol contained questions pertaining to the research objectives and was divided into four parts:

1 background information about the deal and the involvement of the interviewee in it

2 the role of management in integration and knowledge transfer

3 the role of proximity dimensions in knowledge transfer

4 the change in innovative performance after knowledge transfer.

Interviewees were asked to identify how knowledge transfer took place and what factors facilitated or hindered it. They were also asked to identify instances where there was a change in innovative performance as a result of the M\&A. Table 2 provides a profile of the interviewees for each case. All interviews were taped and transcribed verbatim. Coding of the interviews was based on extensive discussions among the members of the research team who reviewed the data and agreed on the categories and sub-categories of importance for understanding the dynamics in the cases. Examples of categories are organisational proximity and cognitive proximity, and examples of sub-categories are base knowledge and domain expertise, which are two components of cognitive proximity. These categories were based on our knowledge of the literature as well as on emergent themes that appeared to be important in understanding the dynamics in the cases.

Data were analysed at two levels: within-case and cross-case analysis (Yin, 2009). The within-case analysis allowed an in depth understanding of each case separately. This was followed by a cross-case analysis where key themes were compared to identify similarities and differences across the cases. As recommended by Miles and Huberman (1994), we used tabular arrangements to summarise and contrast the findings from the three cases. It is important to understand if a particular finding is consistent across cases or is just a one-time phenomenon (Eisenhardt, 1991). This helps strengthen the rigor of the study findings (Eisenhardt and Graebner, 2007). These findings are presented next. 
Table 2 Research participants

\begin{tabular}{|c|c|c|}
\hline Interviewee & $\begin{array}{l}\text { Pre-M\&A } \\
\text { function }\end{array}$ & Notes \\
\hline \multicolumn{3}{|c|}{ GiantSoft and CanSoft } \\
\hline GiantSoft 1 (GS1) & $\begin{array}{l}\text { Integration } \\
\text { manager }\end{array}$ & $\begin{array}{l}\text { Responsible for the integration of CanSoft's products } \\
\text { and their respective development teams into the relevant } \\
\text { product portfolio of GiantSoft's. }\end{array}$ \\
\hline GS2 & Executive & $\begin{array}{l}\text { Responsible for GiantSoft's M\&A activity and for the } \\
\text { worldwide integration of CanSoft and GiantSoft. }\end{array}$ \\
\hline CanSoft 1 (CS1) & $\begin{array}{l}\text { Senior training } \\
\text { specialist }\end{array}$ & Responsible for delivering training. \\
\hline $\mathrm{CS} 2$ & Executive & $\begin{array}{l}\text { Responsible for CanSoft's M\&A activity prior to the } \\
\text { acquisition, and was involved in negotiating the deal. }\end{array}$ \\
\hline $\mathrm{CS} 3$ & CEO & $\begin{array}{l}\text { CanSoft's CEO until the acquisition then became the } \\
\text { general manager for the new division. }\end{array}$ \\
\hline \multicolumn{3}{|c|}{ BrightTech and FutureTech } \\
\hline BrightTech 1 (BT1) & $\begin{array}{l}\text { Product } \\
\text { manager }\end{array}$ & $\begin{array}{l}\text { Involved in post-M\&A integration process and } \\
\text { knowledge transfer }\end{array}$ \\
\hline FutureTech 1 (FT1) & Executive & Responsible for the integration of $R \& D$ teams \\
\hline FT2 & R\&D employee & Worked for FutureTech and stayed after the acquisition \\
\hline \multicolumn{3}{|c|}{ MajCom and NextCom } \\
\hline MajCom 1 (MC1) & $\mathrm{CFO}$ & Responsible for the integration \\
\hline MC2 & $\begin{array}{l}\text { Senior R\&D } \\
\text { employee }\end{array}$ & $\begin{array}{l}\text { Involved in the pre-merger and post-merger technical } \\
\text { meetings }\end{array}$ \\
\hline NextCom 1 (NC1) & $\begin{array}{l}\text { Product } \\
\text { manager }\end{array}$ & $\begin{array}{l}\text { Involved in the pre-merger and post-merger technical } \\
\text { meetings }\end{array}$ \\
\hline $\mathrm{NC} 2$ & $\begin{array}{l}\text { Software } \\
\text { development } \\
\text { manager }\end{array}$ & $\begin{array}{l}\text { Involved in the project with priority resulted from the } \\
\text { merger }\end{array}$ \\
\hline $\mathrm{NC3}$ & $\begin{array}{l}\text { Senior technical } \\
\text { architect }\end{array}$ & $\begin{array}{l}\text { Involved in the pre-merger and post-merger technical } \\
\text { meetings }\end{array}$ \\
\hline
\end{tabular}

\section{Within-case analysis}

In this section, we present the acquisition motive, a description of the integration strategy, analysis of the three proximity dimensions, and outcomes for each of the three acquisitions. Table 3 summarises these elements for each of the three cases.

\subsection{Acquisition of CanSoft by GiantSoft}

The acquisition took place in 2007 as a result of a friendly takeover bid initiated by the acquirer, GiantSoft. Prior to the acquisition, the two firms worked as partners for 12 years. GiantSoft was a multinational firm headquartered in the USA and was a business technology solution provider, offering hardware, software and services. CanSoft was a successful software development company based in Canada and was active in more than 100 countries. It was a market leader in a consolidating market segment that 
provided decision-making support tools for senior managers. GiantSoft was worried that CanSoft might be the next target for competitors. Thus, a strategic acquisition - as it was seen by GiantSoft - was undertaken.

Prior to the acquisition, CanSoft lacked funding to acquire additional capabilities that were vital to its technological expansion. According to the general manager, after the acquisition, GiantSoft invested heavily in CanSoft "because this was an important new area for GiantSoft, which was part of the acquisition plan". An integration team composed of senior employees from both organisations was created to assist with retaining people during the transition. Establishing connections and building relationships to facilitate knowledge transfer was done through two routes, formal and informal. The formal route included setting common product and technical objectives for the technical employees from both firms and enabling them to achieve these objectives. For example, communities were created around key technologies and were led by distinguished engineers who would take the lead in identifying and exploiting new trends in key areas. Informal knowledge transfer happened more spontaneously throughout the integration, when management actively encouraged people to meet in person with their counterparts on site so they could develop close working relationships and thus enhance the flow of knowledge.

The product investment funnel was given as an example of how a new technological opportunity came to be. It started with regular face-to-face meetings between the organisations' research teams to screen for potential opportunities. Once an opportunity was identified, a project team was formed to assess the feasibility. Feasible projects were given the go ahead to undertake further $R \& D$ and product development. To preserve the acquired know-how, GiantSoft retained employees who had a strong understanding of the products, technologies, and markets and eliminated duplicate supporting positions, such as administrative and finance staff.

Table 3 Impact of proximity and management interventions on knowledge transfer and innovation

\begin{tabular}{|c|c|c|c|}
\hline $\begin{array}{l}\text { Dimension and } \\
\text { impact }\end{array}$ & GiantSoft/CanSoft & BrightTech/FutureTech & MajCom/NextCom \\
\hline \multirow[t]{2}{*}{$\begin{array}{l}\text { Geographic } \\
\text { proximity }\end{array}$} & $\begin{array}{l}1.5 \text { hours away; overlap } \\
\text { in time zones }\end{array}$ & $\begin{array}{l}8 \text { hours away; little } \\
\text { overlap in time zones }\end{array}$ & $\begin{array}{l}7 \text { hours away; large } \\
\text { overlap in time zones }\end{array}$ \\
\hline & $\begin{array}{l}\text { Large global firms, and } \\
\text { employees were allowed } \\
\text { to travel }[+]^{*}\end{array}$ & $\begin{array}{l}\text { Employees were allowed } \\
\text { to travel and use } \\
\text { conference facilities [-] }\end{array}$ & $\begin{array}{l}\text { No travel, mainly used } \\
\text { conference facilities to } \\
\text { do knowledge transfer } \\
{[-]}\end{array}$ \\
\hline $\begin{array}{l}\text { Impact on } \\
\text { knowledge } \\
\text { transfer and } \\
\text { innovation }\end{array}$ & $\begin{array}{l}\text { Insignificant negative } \\
\text { impact on knowledge } \\
\text { transfer because of a } \\
\text { large proximity, two } \\
\text { firms were globally } \\
\text { distributed and no } \\
\text { significant involvement } \\
\text { of physical objects }\end{array}$ & $\begin{array}{l}\text { Insignificant negative } \\
\text { impact on knowledge } \\
\text { transfer, which involved } \\
\text { the transfer of an entire } \\
\text { manufacturing facility; } \\
\text { initial disadvantages of } \\
\text { distance were well } \\
\text { addressed by travel and } \\
\text { other communication } \\
\text { means }\end{array}$ & $\begin{array}{l}\text { Significant negative } \\
\text { impact on knowledge } \\
\text { transfer that involved } \\
\text { physical objects; } \\
\text { disadvantages of } \\
\text { distance were not well } \\
\text { addressed due primarily } \\
\text { to a travel freeze }\end{array}$ \\
\hline
\end{tabular}

Note: *The following symbols indicate the level of proximity based on our interpretation of the interviews: $++|+| \pm /-/--$ (where ++ is strongest and -- is weakest). 
Table 3 Impact of proximity and management interventions on knowledge transfer and innovation (continued)

\begin{tabular}{|c|c|c|c|}
\hline $\begin{array}{l}\text { Dimension and } \\
\text { impact }\end{array}$ & GiantSoft/CanSoft & BrightTech/FutureTech & MajCom/NextCom \\
\hline $\begin{array}{l}\text { Cognitive } \\
\text { proximity }\end{array}$ & $\begin{array}{l}\text { Similar base knowledge, } \\
\text { but different domain } \\
\text { expertise }[+]\end{array}$ & $\begin{array}{l}\text { Similar base knowledge } \\
\text { and quite similar domain } \\
\text { expertise (corporate vs. } \\
\text { military applications) } \\
{[++]}\end{array}$ & $\begin{array}{l}\text { Similar base knowledge } \\
\text { and similar domain } \\
\text { expertise (enterprise vs. } \\
\text { small business products) } \\
{[++]}\end{array}$ \\
\hline \multirow[t]{2}{*}{$\begin{array}{l}\text { Impact on } \\
\text { knowledge } \\
\text { transfer and } \\
\text { innovation }\end{array}$} & $\begin{array}{l}\text { The same base } \\
\text { knowledge enabled } \\
\text { employees to } \\
\text { communicate technically } \\
\text { with each other. }\end{array}$ & $\begin{array}{l}\text { The same base } \\
\text { knowledge enabled } \\
\text { employees to } \\
\text { communicate technically } \\
\text { with each other. }\end{array}$ & $\begin{array}{l}\text { The same base } \\
\text { knowledge enabled } \\
\text { employees to } \\
\text { communicate technically } \\
\text { with each other. }\end{array}$ \\
\hline & $\begin{array}{l}\text { The difference in domain } \\
\text { expertise allowed the } \\
\text { companies to explore } \\
\text { new technological } \\
\text { opportunities leading to } \\
\text { radical innovation. }\end{array}$ & $\begin{array}{l}\text { The similarity in domain } \\
\text { expertise allowed the } \\
\text { companies to develop } \\
\text { incremental innovation. }\end{array}$ & $\begin{array}{l}\text { The similarity in domain } \\
\text { expertise allowed the } \\
\text { companies to develop } \\
\text { incremental innovation. }\end{array}$ \\
\hline \multirow{3}{*}{$\begin{array}{l}\text { Organisational } \\
\text { proximity }\end{array}$} & National culture: $[++]$ & National culture: $[++]$ & National culture: $[++]$ \\
\hline & Corporate culture: $[+]$ & Corporate culture: $[ \pm]$ & Corporate culture: $[-]$ \\
\hline & Structure: $[-]$ & Structure: $[ \pm]$ & Structure: $[ \pm]$ \\
\hline $\begin{array}{l}\text { Impact on } \\
\text { knowledge } \\
\text { transfer and } \\
\text { innovation }\end{array}$ & $\begin{array}{l}\text { Large cultural proximity } \\
\text { eased knowledge transfer } \\
\text { but differences in } \\
\text { structure required } \\
\text { adjustments to be made } \\
\text { by CanSoft's employees. } \\
\text { At the same time, } \\
\text { structural differences } \\
\text { helped CanSoft to better } \\
\text { structure its new product } \\
\text { development processes. }\end{array}$ & $\begin{array}{l}\text { Close organizational } \\
\text { proximity eased } \\
\text { knowledge transfer. } \\
\text { There was not a } \\
\text { significant negative } \\
\text { impact experienced } \\
\text { except some ambiguity } \\
\text { and confusion in } \\
\text { communication and } \\
\text { decision-making while } \\
\text { transferring knowledge. }\end{array}$ & $\begin{array}{l}\text { There were both positive } \\
\text { and negative impacts due } \\
\text { to large differences in } \\
\text { corporate culture. This } \\
\text { caused the perception of } \\
\text { exclusion of NextCom } \\
\text { from technical } \\
\text { participation. Positive } \\
\text { impact was that } \\
\text { NextCom adopted a } \\
\text { more flexible approach } \\
\text { to developing new } \\
\text { product and technology. }\end{array}$ \\
\hline
\end{tabular}

Note: *The following symbols indicate the level of proximity based on our interpretation of the interviews: $++/+/ \pm /-/--($ where ++ is strongest and -- is weakest).

\subsubsection{Proximity dimensions}

Geographic proximity is difficult to define with global companies like the acquirer, as they often have multiple divisions with their respective head offices and regional offices, in addition to the corporate headquarters. Difficulties arise around the question of which locations should be taken as the best measurement of distance/proximity. In this case, there were at least three possibilities; CanSoft's headquarters vis-à-vis GiantSoft's headquarters, GiantSoft's software division head office, or GiantSoft's Canadian head office. According to interviewee CS2, the distance between the two companies' headquarters was less than a one hour flight and 20 minutes drive from the airport. For 
GiantSoft/CanSoft, there was no clear evidence that geographic distance impacted knowledge transfer negatively. Several reasons might explain this result.

The first reason is whether or not a company has experience operating in a distributed manner. Global companies, like GiantSoft with numerous offices and R\&D centres around the world, are experienced at dealing with geographical issues.

GS1: "You had two organizations that were used to working in a geographically distributed way. So it wasn't a challenge to have them working together in a geographically distributed way."

Second, GiantSoft made it possible for a core group of employees and managers to travel, where lengthy discussions and face-to-face contacts were required. When travel was not possible, teleconferencing was utilised. Third, GiantSoft developed and invested in infrastructures around collaborative work environments, which enabled global cooperation. On day one, all CanSoft employees were given new laptops, which were equipped with the necessary tools pre-configured to connect to GiantSoft, like the rest of GiantSoft employees.

CS2: "The advantage of our collaborative work environments is that we could continue developing the technologies with several parallel streams but we have to keep in touch with each other to ensure that technologies can be integrated."

However, a downside to substituting face-to-face communication with other means of communication is that it is harder to develop rapport.

CS1: "Video-conferencing or phone calls are used just to save on travel, because it can get expensive, very expensive."

GS2: "If you've got a highly difficult, highly emotional or contentious issue, face-to-face is always going to help get you through it faster, because it's just easier to interact with somebody and solve a problem looking across the table."

\subsubsection{Cognitive proximity}

The two companies were similar in base knowledge (elemental building blocks), but differed considerably in domain expertise (specialisation and depth of know-how). They shared significant similarities in base technologies and practices, as they used common technologies and associated knowledge in the same software development disciplines (e.g., the same programming language and compilers). That resulted in similarity in product architecture, which in turn made collaboration and knowledge transfer easier. CanSoft had always deliberately aligned certain standards with the big players in the industry and GiantSoft was among them. That contributed to their cognitive proximity. The compatibility of technologies and alignment in standards allowed bringing together strengths to improve existing products and develop new products.

CS1: "CanSoft had a long relationship with GiantSoft even before the merger - our software has basically always run on their hardware systems."

While the two companies cooperated in certain areas, they had always focused on their respective fields of expertise; thus there was not much competition or co-development between them. As a result of that, both companies were able to develop their own domain expertise within the software industry, although in different technological realms. Dissimilarities in domain expertise and their previous partnership made the acquisition a quick fit in terms of product and technology and thus minimised the amount of work 
required to integrate them. At the same time, dissimilarities in domain expertise increased the opportunity for radical innovation.

GS2: "It's the application of that technology in the domain that differentiated them. The CanSoft team was looked at for that domain expertise. So clearly we valued it and they are the subject matter experts."

CS1: "There is an instant fit between our technologies and their technologies. And there wasn't a lot of work required to actually merge the two of them together, because of the fact that GiantSoft was buying technology that it didn't have, but the cogs of the wheel basically fit together beautifully."

\subsubsection{Organisational proximity}

At the national cultural level, it was pointed out that although there are minor differences between the mindsets of Canadians and Americans, the differences were not significant from a knowledge transfer standpoint. The corporate similarities and differences were considered to be more relevant. At the corporate level, one of the similarities was the collective mentality toward innovation, characterised as trying to lead rather than follow the industry.

CS1: "CanSoft is always known for being leading edge. We are not in the industry to follow other people; we are in the industry to lead. GiantSoft is the same thing."

On the other hand, the organisations differed in several respects, such as employees' attire, working hours, and entrepreneurial orientation. For example, CanSoft was more entrepreneurial and new ideas were more likely to be embraced and resulted in new projects. Moreover, there were differences regarding the use of open-source technology. GiantSoft had a strict policy, which resulted in the immediate elimination and replacement of all open-sourced technologies from CanSoft's products.

These cultural differences were seldom detrimental to knowledge transfer. The results might be credited to measures taken by management before and after the acquisition; GiantSoft invested heavily in cultural aspects of integration. It implemented programmes to assess and promote understanding of differences and that helped to resolve conflicts quickly.

GS2: "We invested very heavily in understanding the cultural differences, the impact that our plans would have on the cultural differences and what those cultural differences would mean."

CS3: "Those resulted in action plans to address what we could address. So the whole process was about letting people get the stuff off their chest and identifying deficiencies in the process from people who saw it happening."

CS2: "Culturally it's been amazing when people are focused on an idea of creating value; that's what they're focused on and cultural differences just step aside."

Structural differences also affected knowledge transfer positively and negatively. In terms of positive differences, GiantSoft had a more structured product development process which CanSoft was planning to implement, and thus the acquisition only accelerated the change. On the other hand, differences in size and lines of responsibility had a negative impact on knowledge transfer. GiantSoft, being about ten times larger than CanSoft and active in software, hardware, and services, had a more complex structure 
than CanSoft, which was primarily in the software business. GiantSoft also had more checks and balances in its product development process. For CanSoft, it was a major change in structure from clear lines of responsibility to a matrix that required adjustment and slowed down the speed at which decisions were made.

GS2: "Taking an organization that is self-contained and then helping those people understand how to succeed inside a highly matrix-managed organization, takes time."

CS1: "I look at our company intranet and I look at the GiantSoft intranet - it was like going from our own little system, to the World Wide Web!"

The difference in size and structure posed three challenges for knowledge transfer. First, it was hard for CanSoft employees to connect to their counterparts at GiantSoft. In some cases, several phone calls were needed to find the right person, which was detrimental to knowledge transfer. Some people simply gave up or delayed contacting people they needed to speak with. Second, being acquired by GiantSoft meant a loss of flexibility and speed to CanSoft. The sudden increase in size affected the time from initial idea to commercialisation of a product, because there were more steps to go through.

CS3: "In a smaller company, a lot of knowledge transfer was done very informally... You didn't have to worry about certain processes that are normal for a very big company."

Third, GiantSoft's size made it harder to create awareness of CanSoft's technological knowledge. Individuals from other parts of GiantSoft were often not aware of what CanSoft did. This limited CanSoft's knowledge being leveraged in other parts of GiantSoft. CanSoft's management proactively shifted its people into GiantSoft and delivered presentations to create awareness, which helped.

CS2: "One of the biggest challenges we have as a unit within GiantSoft is creating awareness around what our products can do; a number of people are surprised like, 'In addition to business intelligence you guys do financial stuff too?"”

\subsubsection{Outcome}

The acquisition was deemed successful by both organisations; CanSoft was 'seamlessly integrated' into GiantSoft as interviewee CS1 indicated. The once small partner that helped to optimise GiantSoft's products had become the leading unit of a sector within GiantSoft's Software Group. GiantSoft successfully retained the majority of CanSoft's employees. The retention of these employees promoted knowledge transfer resulting in both incremental and radical innovations. Incremental innovation came from combining and enhancing existing product and technology. After the acquisition, access to each other's knowledge and capabilities enabled the partners to learn and improve their products.

CS3: "We now ship our product working on one of their servers, which we had never done before. We were only able to do that with access to the hardware and the skills, so that's a new thing."

In addition, CanSoft gained access to GiantSoft's research capabilities such as R\&D labs, pre-market technologies, and intellectual property rights, which accelerated its development progress for certain forward-looking concepts and reduced project expenses. 
It was also able to commercialise research technology coming from GiantSoft's R\&D lab. Access to GiantSoft's technological knowledge base contributed to CanSoft's ability to a) exploit existing knowledge and capabilities of GiantSoft, and b) to explore new technological opportunities (radical innovation).

CS3: "(We had) access to technologies, which we otherwise would have to license from other companies, to combine with our products to make a bigger solution."

CS3: "We are just on the verge of launching a whole new product around social networking capabilities, which came about as a result of some research technology of GiantSoft that we're commercializing."

Moreover, as part of GiantSoft, CanSoft leveraged GiantSoft's brand to participate in larger projects that were not feasible due to a lack of credibility as a small firm. GiantSoft's brand gave them the credibility, legitimacy and capability to take on transformational initiatives, which gave them "a massive push forward into the next generation of software" as interviewee GS1 stated.

CS2: "So those large and truly transformational initiatives ... we just would not have the resources to either create on our own or even, in some cases, participate in."

\subsection{Acquisition of FutureTech by BrightTech}

This case involves the acquisition of Canada-based FutureTech by BrightTech from the UK. The acquisition took place in 2002 following the high-tech bubble burst. FutureTech was a subsidiary created by GrandFuture by pooling together a number of optical components units, including some externally acquired. Optical components, at the time, were seen as the backbone to the future of super-fast internet traffic and so business boomed. But when the market for optical components collapsed, FutureTech was put up for sale. BrightTech, an equally hard-hit optical component supplier, agreed to purchase FutureTech. BrightTech designed and manufactured high performance optical internet communications products. BrightTech acquired FutureTech because it was active in the same business and FutureTech's technologies were more mature than BrightTech's, which provided the latter with technological advances. By acquiring and combining FutureTech's knowledge and capabilities with its own, BrightTech was aiming to become a major player in this industry, offering a full range of products from components to complete systems. The acquisition was expected to yield synergies by reducing operating costs and R\&D expenditures.

Senior managers from FutureTech and BrightTech discussed the integration plan, which included a decision to close the manufacturing facility in Canada and to transfer all products and manufacturing equipment to the UK. As part of the integration plan, management offered significant bonuses in order to retain all R\&D employees at the design facility and most of the manufacturing employees - some of them on a temporary basis - to perform the knowledge transfer. The design facility in Canada was kept intact; it would be cooperating over a large distance with the new facility in the UK. To encourage cooperation and create a sense of belonging to a team, management implemented a 'one team approach.' Some travel and face-to-face meetings were organised, along with intranet and conferencing facilities. 


\subsubsection{Proximity dimensions}

\subsubsection{Geographic proximity}

The distance was, in some respects, a disadvantage to the flow of knowledge between the two companies' R\&D and manufacturing teams. The difference in time zones and some 3,000 miles between BrightTech and FutureTech formed a barrier to the flow of know-how. First, it hindered employees from developing working relationships and building trust. Face-to-face contact, in particular, was seen as vital to establishing trust and close working relationships. In addition, because the transfer of the manufacturing facility involved physical objects, it required technical people to travel and share their experience.

FT1: "A lot of info you can only transfer by being there talking and looking at things. It's difficult to do that on the phone. There is a limit to what you can do."

BT1: "For the knowledge transfer... the main thing is that you develop a relationship with people from the other end. Once you have built a relationship, you feel like you are on the same team and working toward the same goal."

The interviewees believed that geographic distance also affected tacit knowledge being transferred, because this type of knowledge held by people could only be learned and shared when they were physically present to participate in it. However, when transferring explicit knowledge, which could be more easily documented, geographic proximity was less problematic. Further, being in different time zones worked against the transfer of knowledge because it prevented effective communication during regular business hours. Nevertheless, morning hours in the Canadian office overlapped with afternoon hours in the UK, and the overlap was used to hold conference calls.

Travel between the two locations was particularly important when transferring the manufacturing technologies and the associated knowledge from Canada to the UK. Although travel reduced the disadvantages of physical distance, it was costly and received little commitment from the employees as it proved tiresome. In instances where travel could be avoided, BrightTech made video conferencing facilities available so that employees from both sides could communicate freely.

FT2: "Senior people travelled more often; they would go to the other side when there was a lack of knowledge."

\subsubsection{Cognitive proximity}

Interviewees indicated that there were few differences in technological knowledge between the two firms. Similarities in base knowledge eased knowledge sharing, because employees were able to communicate technological issues freely. They were also similar in terms of the employees' skills, training, and experiences, although they were serving different types of customers. FutureTech had more corporate customers, while BrightTech had more military contracts, so there was not much overlap in product offerings. The overlap in skill sets and being active in the same technologies suggests minimal differences in domain expertise. This limited BrightTech's ability to develop radical innovations, although BrightTech was able to combine FutureTech's knowledge and capabilities to introduce incremental product innovations. 
FT1: "The base technology was common. In other words, the people spoke the same language. They weren't trying to transfer knowledge that nobody understands."

BT1: "As to the base knowledge, the university degrees of the employees, and the amount of experience were very similar."

Organisational proximity. In terms of cultural proximity, there were both similarities and differences at national and corporate levels. The two companies shared much in common at the national culture level, because Canada and the UK are quite alike.

FT1: "There are some differences, but culturally UK and Canada have some fairly strong similarities, and they spoke the same language."

At the corporate level, cultures diverged slightly more but were not seen as having a significant impact on knowledge transfer. The two firms differed more significantly in structure, such as reporting style, hierarchical structure, and role fulfilment by employees and managers. According to interviewee FT2, there was a chain-of-command hierarchy at BrightTech; employees needed permission from managers before doing something new whereas at FutureTech employees had more freedom.

FT2: "In North America, reporting structure is very relaxed, whereas in Europe, it's more a chain-of-command."

Interviewees experienced some confusion and difficulties in communications because of the differences in organisation structures. Employees did not always know who the decision-maker was and who to talk to when they needed something, and as a result, employees voiced in a mid-merger survey that there was a need for clear job descriptions and an organisational chart, so people from both sides knew who was doing what, and whom to turn to when needed. Interviewees noted that closer organisational proximity (e.g., similar organisation structure, and role/job descriptions) would have minimised miscommunication.

Outcome. BrightTech gained access to FutureTech's customers mainly in North America, as well as the knowledge and capability to serve them. The transfer of products and technology, including the manufacturing facility from Canada to the UK was deemed successful. BrightTech retained most of the R\&D employees and those working at the manufacturing facility for the short term. In the end, no significant turnover was experienced.

BT1: "That enabled us to create a large portfolio of products to serve a broader customer base."

FT1: "We transferred successfully all the products we wanted to transfer to the UK and we started new products."

As a result of the transfer of knowledge and capabilities, BrightTech's capacity to produce incremental innovation increased substantially but radical innovation was elusive. The new company doubled the number of highly qualified engineers and the stock of technologies. In addition, the significant number of patents and technological knowledge transferred accelerated product development processes at BrightTech. BrightTech brought out many technologically enhanced laser products, based on technological knowledge and capabilities transferred from FutureTech. 
FT1: "There was a lot of knowledge transfer interaction around the various products, which enhanced their functionalities."

BT1: "The products and production technologies were all transferred. So that was what BrightTech was buying; BrightTech was buying the know-how and the product line."

\subsection{Merger between MajCom and NextCom}

This case involves the 2007 acquisition of US-based NextCom by Canada-based MajCom, although officially the deal was dubbed a merger of equals. ${ }^{1}$ Both MajCom and NextCom were active in the telecommunication equipment market. MajCom's main reason to acquire/merge with NextCom - one of its competitors based in the USA - was to gain market share. Traditionally, MajCom had been successful in the enterprise market space and had about $40 \%$ of its sales in the USA. NextCom, on the other hand, was stronger in the small business space and had about $90 \%$ of its sales in the USA. By merging with NextCom, MajCom could capitalise on NextCom's strong sales and service organisation to expand its existing sales channels. Moreover, the merger would yield compelling operating synergies, as well as give the new company more bargaining power with its stakeholders.

The integration occurred mainly between MajCom teams responsible for small business products and NextCom's US R\&D and product teams, which also focused on small business products. This meant that small business product portfolios needed to be consolidated, and this included a decision to terminate one of NextCom's two key projects to develop the next generation technology that would replace the current technology.

Integration was formally led by a team composed of ten leaders from each organisation who were assigned by the integration manager and CFO of MajCom to oversee integration for every function. A key objective was to move the two companies onto one system and one process. Progress was tracked in a monthly conference call. In the R\&D area, most integration decisions came from MajCom as to what needed to be done. According to NextCom interviewees, they were mostly told what to do to make the new MajCom successful. This had an impact on how NextCom's knowledge was transferred and used. Upon the merger, the training centres on both sides were enabled to provide training on each other's products, so that technical employees from both sides understood how things worked on the other side. It was believed that a good understanding of product and technology would allow for finding leverage points across the organisation.

The new company did not intend to retain NextCom's technical employees associated with the terminated project but to retain those technical employees associated with the continuing project. Some people who were deemed to be important were given greater incentives, and were also more likely to be promoted. Despite the bonuses and stock grants, many NextCom technical employees associated with the continuing project left. NextCom's interviewees felt that the loss of technical employees with a lot of knowledge and expertise hurt the new MajCom's ability to work on next generation variations of the merged products. 


\subsubsection{Proximity dimensions}

\subsubsection{Geographic proximity}

The distance between the organisations was seven hours by airplane. The distance had an impact on knowledge transfer, despite the fact that the two firms had some global operations. MajCom had a large percentage of their revenue generated outside its home-country, while NextCom had offices around the world. Interviewees suggested that if there were greater physical proximity, i.e., co-location, there would have been more fruitful collaboration due to more face-to-face contact.

\footnotetext{
MC1: "It wasn't new to us in terms of having the challenges of managing an international company, but is certainly more challenging than if all your people are down the hall."

NC2: "Most of the knowledge sharing had to be done over the phone, or by sharing documents, things like that, which wasn't as efficient as having the ability to kind of go back and forth and have a discussion on the technical topic."

NC1: "You can ship hardware back and forth, and then work on it remotely, but it's not the same as being in that environment."
}

To mitigate geographic barriers, initially, key technical people travelled along with the management team. With the economic downturn, travel was cut and replaced with video-conferencing. Though video conferencing allowed people to see and interact with each other, it did not provide for as much interaction as meeting in person and neither did it help foster close working relationships. Thus, the benefits from collaboration were diminished. On the other hand, the time zone overlap permitted people from the two organisations to have video conferences and e-mail exchanges. Interviewee NC3 stated that if there was less or no overlap in time zones, communication would have been more difficult.

\subsubsection{Cognitive proximity}

Prior to the merger the two firms were competitors; thus they were close in cognitive proximity. Both were active in the same technical field offering comparable products. The difference between them was in the markets served.

\section{MC1: "NextCom folks had a good knowledge of what a small business user needed, and the MajCom R\&D people didn't understand that market that well, but had a better knowledge of what bigger customers needed."}

In spite of different technical strengths for different market segments, the two companies had a presence in each of the markets. Presence in the same markets limited the firms' ability to substantially enhance their products and domain expertise. During the integration, the overlapping product portfolios and technologies needed to be reconciled, and this led to the termination of a NextCom project, which was seen as technically advanced and interesting by interviewees from both organisations. It suggested MajCom lacked the ability to properly understand the terminated project and what its impact would be. Further, despite the significant cognitive overlap, minor differences existed in terminology usage and in how certain codes and files were stored. The differences caused frustration in the sharing of knowledge though efforts to work toward common tools and processes led to better alignment. 


\subsubsection{Organisational proximity}

No significant structural or national cultural differences that impacted knowledge transfer were identified.

$\mathrm{MC1}$ : "The Canadian business culture and US business culture, as well as rules
and regulations, aren't all that different."

At the corporate level, cultural differences were greater in terms of product development process, views on the product life cycle, work environment, and participation. At NextCom, there was a management culture that was strict in terms of meeting product milestones and release schedules and little tolerance for delays in the product development process. In addition, NextCom's product design phase tended to include more technical details to minimise technical risks and delays in product release, but the extensive design approach made the process rigid and time consuming. It was difficult to add an additional feature to a product that had passed the design phase. Design changes were required to go through a series of formal procedures that were lengthy and complex.

\footnotetext{
NC3: "NextCom was more aware of trying to be more efficient, trying to plan things out to the nth degree, like over-engineering things. Because you're trying to consider so many different things, it's going to take longer."

MC2: "NextCom people would do a lot of the development during the analysis/design stage which would de-risk their schedules... so their schedules are much longer but they also have more predictability."
}

NextCom's culture of over-engineering and strict time commitment led it to be more conservative in terms of developing new products and technologies, and in some cases to be less productive. After the merger, NextCom moved away from the strictness, which according to the interviewees was preferable for producing a better output. A second difference was that NextCom had a view that every technology has a limited/finite life, whereas MajCom viewed that each product and technology could be continually developed and enhanced. At NextCom, products were developed according to their expected life, and thus there was no effort or money invested beyond the product's life expectancy. When MajCom merged its 'long living' products with NextCom's products that were near the end of their life cycle, there were problems that complicated collaboration.

\section{NC1: "NextCom believed that there is a lifecycle of a product, whereas MajCom believed that existing products can be continuously evolved."}

A third difference was that NextCom had a more family-like environment, where everybody knows everybody else, and people seemed willing to help out if asked. At MajCom, people appeared to be less willing or available to provide assistance.

NC2: "If somebody asks for help, usually the other people would help out, even though they might have some other tasks they need to be working on. But when we ask somebody in Canada for help, we might get a response of 'You need to get it on my to-do list before I'll look at it'."

MC2: "At NextCom, everyone seemed to know everyone. Some of the people at NextCom were often surprised that I didn't seem to know all the people who worked at MajCom.” 


\subsubsection{Outcome}

The merger has been successful in terms of achieving the original intention for the deal (increase market share). It led to the elimination of a key competitor for MajCom in the US market. It gained a stronger market footprint and access to a strong sales organisation, as well as the attractive service model of NextCom. However, in terms of retaining key people, it had not been successful. It lost many technical employees associated with the continuing project, which MajCom wanted to retain. This loss hurt its ability to innovate.

In terms of innovation resulting from the combination of technological knowledge and capabilities, there were incremental improvements in product, technology, and research process. An increase in development speed was the result of the large technology pool from which to draw the best technology, and a larger technical employee base. Post-merger, MajCom leveraged the strengths of the two organisations to provide a stronger portfolio. Interviewees stated that without the merger MajCom would not have been able to introduce a new, enhanced product portfolio so quickly for the small business market. New-found strengths allowed optimisation of the product portfolio.

MC1: "We've created new products; we've taken products that were kind of tired and just rejuvenated them with some new features and functionalities as opposed to starting it all from scratch."

NC1: "We were able to create a combined portfolio out of the strengths of our products and use the complementary products from the other side to strengthen points in which we were weak. So, I think it's given us a much fuller portfolio and stronger position across the board... I would say neither company could have gotten those capabilities introduced into their portfolios without the merger."

MC2: "We were able to get new products up and running on their systems in one year or less, which is quite good... I think we're able to get product... in a year, as opposed to three or four years as it would've been otherwise."

The merger did not result in radical innovations. Several explanations were offered. First, geographic distance between the companies was a barrier to more fruitful knowledge sharing, especially when the economy went into recession, and travel budgets were cut. Second, organisational differences prevented knowledge from being effectively leveraged. Some technical teams at MajCom worked alone and shut out those who might have contributed to product development. Third, the overlap in technologies and product portfolios meant limited complementarity. There were too few complementary technologies and skills to allow for recombination of technologies. In addition, some product lines were consolidated or discontinued and the employees working on these products had to be shifted or eliminated. MajCom might not have fully understood NextCom's next generation technology. The potential of that technology and the technical people associated with it were mostly lost. 


\section{Results and discussion}

\subsection{Proximity and management interventions}

\subsubsection{Geographic proximity}

Each of the cases indicates a relationship between geographic proximity and knowledge transfer. In keeping with prior studies (Ensign, 2009; Saxenian, 1994), geographic proximity has a positive impact on knowledge transfer. As described in Table 3, in the case of GiantSoft/CanSoft, distance did not adversely impact knowledge transfer and innovation. The challenges of distance were overcome by utilising travel and video conferencing. Being a large globally distributed company does not make face-to-face contact irrelevant or less important but reinforces that companies must recognise the role of interpersonal dynamics in the transfer of tacit knowledge (Laamanen and Autio, 1996).

Unlike GiantSoft/CanSoft, knowledge transfer in the other cases was more challenging due to the large distances. The employees of the newly combined MajCom did not cope well with the distance and this had a negative impact on knowledge transfer. A travel freeze imposed by the new management team did not help either. As indicated by interviewees at NextCom, the collaborative effort would have been more successful if there were more opportunities to meet MajCom employees. Dickson (1996) proposes that technology-intensive, rapidly internationalising firms need to build rapid trust for establishing successful collaboration. Such trust is built and evaluated quickly through intense interaction, shared vision, and an appreciation of the other's complementary knowledge (Coles et al., 2003).

For BrightTech/FutureTech, distance was even greater. But the distance barrier was effectively diminished primarily by employee travel. A comparison of how post-M\&A MajCom and BrightTech dealt with distance suggests that physical distance can be mitigated by travel in addition to modern communication tools and management intervention.

Our results indicate that if employees from both organisations build trust and develop good working relationships, then the transfer of knowledge and capabilities will be effective. Face-to-face contact and co-location foster social interaction, which accelerates trust and relationship building. Information and communications tools such as video conferencing, are useful mainly after initial personal contact is established and some level of social interaction has taken place. This evidence is inconsistent with Cairncross's (1997) claim that distance is no longer relevant. Thus, our first propositions emerge:

Proposition 1 Geographic proximity promotes knowledge transfer and innovation.

Proposition 2 The negative ramifications of geographic distance on collaborative activity may be moderated by social ties, structural connection, and systems put in place by management.

\subsubsection{Cognitive proximity}

In terms of cognitive proximity, two aspects arise: base knowledge and domain expertise. The distinction between base knowledge and domain expertise has not been well established empirically (Ensign, 1999; Iansiti, 1995). Most studies are conceptualised around the relatedness of technological knowledge and to a lesser extent the complementarity of technological knowledge. 
Interviewees suggested that overlapping base knowledge is important for communicating technical knowledge; that is, they need to have common fundamental scientific and technical principles (e.g., the same programming language for software developing companies), or they need to be in the same or closely related industry. This is in line with the theory of absorptive capacity (Cohen and Levinthal, 1990), which posits that a minimum level of common knowledge is required to communicate with and to absorb knowledge from another. If not, transfer and leverage of knowledge and capabilities is unlikely and cumbersome.

Domain expertise is the firm's knowledge and capabilities specific to a technological field. When two companies with dissimilar domain expertise merge there is opportunity to explore new technology due to available complementary knowledge and capabilities (Graebner et al., 2010). However, it should be noted that there could be complementarities in M\&A between firms in the same technological domain and between those in different domains. Firms in the same domain might have knowledge and capabilities to complement each other, despite some overlap. This was seen in all three cases, where the most advanced technology or capability was leveraged to create new or to enhance existing products. This illustrates how the combination of two closely related companies leads to incremental innovation. On the other hand, differences in domain expertise could provide a higher level of complementarity in knowledge and capabilities to the new company, which could disrupt existing technology development. Consequently, combining firms with common knowledge/capabilities would be more likely to result in incremental innovation; whereas combining firms with distinct yet complementary domain expertise would more likely lead to radical innovation or strategic renewal (Graebner et al., 2010).

At both MajCom/NextCom and BrightTech/FutureTech the impact was mainly in terms of incremental innovation, since they had the same domain expertise. There was insufficient complementary knowledge and capabilities to allow for exploration of radically new technological opportunities. In the case of GiantSoft/CanSoft, there were substantial differences in domain expertise that provided complementary knowledge and capabilities that GiantSoft leveraged to create radical innovation. Following the above logic, and based on the empirical findings, it is proposed:

Proposition 3 Similarity in base knowledge is positively associated with knowledge transfer.

Proposition 4 Similarity in base knowledge is positively associated with incremental innovation.

Proposition 5 Dissimilarity in domain expertise is positively associated with radical innovation.

\subsubsection{Organisational proximity}

It was found that individual aspects of organisational proximity, i.e., national and corporate culture, and structure seemed to impact knowledge transfer. Generally, speaking, the greater the proximity (similarity in each of the aspects), the smoother the transfer of knowledge because fewer adjustments are required from both parties.

On the structural side, differences required initial adjustments on the part of employees. CanSoft employees needed to adapt to GiantSoft's more complex 
organisational structure. It was difficult for some CanSoft workers to find their counterparts. The more established structure at GiantSoft slowed the decision making process. In addition, due to the difference in size, it was hard for CanSoft to get its technological capability known and fully understood by the rest of GiantSoft. It required CanSoft's proactive engagement to get itself 'promoted' and accepted within the new organisation. This is in keeping with Chen et al.'s (2011, p.39) view that beyond sharing similar knowledge bases, participation in an articulation process is necessary to know where the desired knowledge resides. In the other two cases, structural differences were smaller and, in general, did not significantly impede knowledge transfer.

It can be concluded that greater organisational proximity is desirable for knowledge transfer because it minimises uncertainty and confusion when employees from both firms interact. A lack of organisational proximity requires time and effort for employees to adapt to the new organisational setting. In some instances if the differences are considerable, the process of transferring knowledge could be challenging. Lubatkin (1983) and Datta (1991) have suggested that organisational incompatibilities, such as differences in management style, organisational structure, and culture, affect post-M\&A integration and cause problems in the realisation of benefits to M\&A.

However, there are situations when different organisational environments could provide opportunities for learning, as discussed in the case of MajCom/NextCom, where NextCom adopted a more flexible approach in its product development process from MajCom. A similar situation was seen in the case of GiantSoft/CanSoft, where there were stark contrasts in the firms' structures. However, the structural issues were proactively dealt with. As a result, the negative impact of structural differences on knowledge transfer was minimised; at the same time, the differences contributed to a quicker adoption of a more structured product development process by CanSoft, which eventually helped CanSoft to improve its innovative productivity within the combined firm.

This finding suggests that when there is a shift toward a better process or cultural aspect, it can affect the new firm's innovative productivity favourably, providing the process is well-managed. This observation is in line with Calderini and Garrone's (2003) work which suggests that organisational differences may foster the learning process, especially in R\&D functions. Similarly, Barkema and Vermeulen (1998) and Vermeulen and Barkema (2001) reported that organisational diversity (i.e., differences in cultures and systems) can help companies become less rigid and to develop knowledge structures that will enhance innovation and learning. Our findings suggest that management intervention is key to achieving these ends and our final propositions are derived:

Proposition 6 Organisational proximity promotes knowledge transfer and innovation.

Proposition 7 The negative ramifications of organisational distance on collaborative activity may be moderated by social ties, structural connection, and systems put in place by management.

\subsection{Knowledge transfer and innovation outcome ${ }^{2}$}

GiantSoft/CanSoft and BrightTech/FutureTech were successful in their knowledge transfer efforts and MajCom was only moderately successful (see Table 4). The proximity dimensions - geographic, cognitive, and organisational - as well as the retention of key employees influence the level of success achieved. In the MajCom case, knowledge transfer was moderately successful because it lost a significant number of 
technical employees associated with ongoing projects that the new management wanted to retain. Similarly, most of NextCom's senior managers left the company. These managers could have provided needed stability and continuity post-M\&A. They could have also played a role in realising post-M\&A value, both expected and serendipitous (Graebner, 2004).

Change in innovative performance is also shown in Table 4. For incremental innovations, there are four different categories of change identified that are similar to those suggested by Man and Duysters (2005), although in more detail. These categories are product optimisation, that is using the combined technological knowledge and capabilities to enhance product capability and features; product recombination, that is using combined knowledge and capabilities to create new types of products; acceleration of product development (due to access to research facilities and a large pool of capable employees); and enhancement in the firm's $R \& D$ practices that improve productivity (such as, the adaptation of more structured R\&D processes by CanSoft and more lenient product development processes by NextCom).

Although in all three cases incremental innovations were associated with the transfer of knowledge, GiantSoft/CanSoft was the most successful. CanSoft not only had various types of incremental innovation, it also had the opportunity to create new products by tapping into GiantSoft's large knowledge base, where there was unused research and knowledge. On the other hand, BrightTech and MajCom mostly created incremental innovations based on the optimisation of existing products. The firms leveraged each other's technical strengths to increase the performance of their products and technology. For example, BrightTech was able to leverage some of FutureTech's proven technology to accelerate its development process around various laser products.

Table 4 Knowledge transfer and innovation outcome

\begin{tabular}{|c|c|c|c|}
\hline & GiantSoft/CanSoft & BrightTech/FutureTech & MajCom/NextCom \\
\hline $\begin{array}{l}\text { Knowledge } \\
\text { transfer }\end{array}$ & Successful & Successful & Somewhat successful \\
\hline \multirow[t]{8}{*}{ Reasons } & \multirow[t]{2}{*}{$\begin{array}{l}\text { Large geographic } \\
\text { proximity with a small } \\
\text { distance that was } \\
\text { addressed. }\end{array}$} & $\begin{array}{l}\text { Small geographic } \\
\text { proximity with a distance } \\
\text { that was addressed. }\end{array}$ & $\begin{array}{l}\text { Small geographic } \\
\text { proximity but distance not } \\
\text { effectively addressed. }\end{array}$ \\
\hline & & Similarity in base & Similarity in base \\
\hline & \multirow{2}{*}{$\begin{array}{l}\text { Similarity in base } \\
\text { knowledge allowed for } \\
\text { communication, while } \\
\text { dissimilarity in domain } \\
\text { expertise allowed for } \\
\text { radical innovation. }\end{array}$} & $\begin{array}{l}\text { knowledge allowed for } \\
\text { communication, there is } \\
\text { little dissimilarity in } \\
\text { domain expertise. }\end{array}$ & $\begin{array}{l}\text { knowledge allowed for } \\
\text { communication, but a lack } \\
\text { of dissimilarity in domain } \\
\text { expertise led to }\end{array}$ \\
\hline & & $\begin{array}{l}\text { Relatively large } \\
\text { organisational proximity }\end{array}$ & $\begin{array}{l}\text { termination of some } \\
\text { projects and people, }\end{array}$ \\
\hline & \multirow{2}{*}{$\begin{array}{l}\text { Large organisational } \\
\text { proximity that eased } \\
\text { knowledge transfer but } \\
\text { required some } \\
\text { adjustments. }\end{array}$} & $\begin{array}{l}\text { eased the knowledge } \\
\text { transfer. }\end{array}$ & $\begin{array}{l}\text { Wnich caused retention } \\
\text { issues. }\end{array}$ \\
\hline & & $\begin{array}{l}\text { Successful resolutions of } \\
\text { retention issues. }\end{array}$ & $\begin{array}{l}\text { Differences in } \\
\text { organisational proximity } \\
\text { were both positively and }\end{array}$ \\
\hline & \multirow{2}{*}{$\begin{array}{l}\text { Successful resolutions of } \\
\text { retention issues eliminate } \\
\text { their negative impact on } \\
\text { knowledge transfer. }\end{array}$} & & $\begin{array}{l}\text { negatively associated with } \\
\text { knowledge transfer. }\end{array}$ \\
\hline & & & $\begin{array}{l}\text { Retention issues were not } \\
\text { effectively addressed. }\end{array}$ \\
\hline
\end{tabular}


Table 4 Knowledge transfer and innovation outcome (continued)

\begin{tabular}{|c|c|c|c|}
\hline & GiantSoft/CanSoft & BrightTech/FutureTech & MajCom/NextCom \\
\hline \multirow{6}{*}{$\begin{array}{l}\text { Incremental } \\
\text { innovation }\end{array}$} & Product optimisation & \multirow{6}{*}{$\begin{array}{l}\text { Product optimisation. } \\
\text { Product recombination. } \\
\text { Acceleration of product } \\
\text { development (access to } \\
\text { proven technology). }\end{array}$} & Product optimisation. \\
\hline & (improved products). & & \multirow{5}{*}{$\begin{array}{l}\text { Acceleration of product } \\
\text { development (larger pool } \\
\text { of knowledge and } \\
\text { technology). } \\
\text { Enhanced R\&D practice. }\end{array}$} \\
\hline & $\begin{array}{l}\text { Product recombination } \\
\text { (new products). }\end{array}$ & & \\
\hline & Acceleration of product & & \\
\hline & $\begin{array}{l}\text { development (access to } \\
\text { research capabilities and } \\
\text { unused research findings. }\end{array}$ & & \\
\hline & Enhanced R\&D practice. & & \\
\hline \multirow[t]{2}{*}{$\begin{array}{l}\text { Enabling } \\
\text { factors }\end{array}$} & $\begin{array}{l}\text { Prior partnership and } \\
\text { similar base knowledge. }\end{array}$ & \multirow{2}{*}{$\begin{array}{l}\text { Active in the same } \\
\text { industrial } \\
\text { domain/technological } \\
\text { area, the acquired } \\
\text { company's proven } \\
\text { technology. }\end{array}$} & \multirow{2}{*}{$\begin{array}{l}\text { Active in the same } \\
\text { industrial } \\
\text { domain/technological } \\
\text { area. }\end{array}$} \\
\hline & $\begin{array}{l}\text { Untapped research } \\
\text { knowledge of the } \\
\text { acquirer, large knowledge } \\
\text { base of the acquirer. }\end{array}$ & & \\
\hline $\begin{array}{l}\text { Radical } \\
\text { innovation }\end{array}$ & $\begin{array}{l}\text { Exploring new or next } \\
\text { generation technology, } \\
\text { adding completely new } \\
\text { capability (acquisition of } \\
\text { a third high-tech } \\
\text { company), leveraging the } \\
\text { acquirer's reputation to } \\
\text { initiate projects that could } \\
\text { transform the market } \\
\text { place. }\end{array}$ & \multirow[t]{2}{*}{ N/A } & \multirow[t]{2}{*}{ N/A } \\
\hline $\begin{array}{l}\text { Enabling } \\
\text { factors }\end{array}$ & $\begin{array}{l}\text { Large difference in } \\
\text { domain expertise, } \\
\text { availability of acquirer's } \\
\text { resources and reputation. }\end{array}$ & & \\
\hline $\begin{array}{l}\text { Inhibiting } \\
\text { factors }\end{array}$ & & $\begin{array}{l}\text { Too much overlap in two } \\
\text { companies knowledge and } \\
\text { capabilities; too little } \\
\text { difference in domain } \\
\text { expertise. }\end{array}$ & $\begin{array}{l}\text { Too much overlap in two } \\
\text { companies knowledge and } \\
\text { capabilities; too little } \\
\text { difference in domain } \\
\text { expertise; divergent } \\
\text { strategic intent/focus. }\end{array}$ \\
\hline
\end{tabular}

GiantSoft was the only company that experienced radical innovation. It explored next generation technology and launched products in new fields. CanSoft, as a new unit within GiantSoft, was also able to take on projects that could change the marketplace by leveraging GiantSoft's credibility and capabilities.

Our results lend support to the conclusion drawn by Makri et al. (2010) that knowledge transfer in M\&A between firms with similar knowledge bases is positively related to incremental innovation, while knowledge transfer between firms with complementary technology and capabilities is positively related to radical innovation. Similarly, studies on R\&D alliances found that when the knowledge bases between partners are too similar, there is little benefit to radical innovation but when technical knowledge is complementary, the benefits to radical innovation are greater (Quintana and Benavides, 2010). 


\section{Conclusions}

\subsection{Summary and implications}

Building on prior research on intra- and inter-organisational knowledge transfer, this study investigated the impact of three proximity dimensions as well as management interventions on M\&A knowledge transfer and innovation. Evidence from three M\&A cases, where technology-based companies were involved, supports the links between various dimensions of proximity (i.e., geographic, cognitive, and organisational) and knowledge transfer, and between knowledge transfer and innovation.

Close physical proximity made it easier for personal interactions, which helped build trust and strong relationships, both of which were of major importance in transferring knowledge. Management could mitigate potential negative effects of geographic distance by allowing employees to travel and meet face-to-face. Of course, this option is more costly and requires greater expenditures of time and effort on the part of the company and employees.

It was found that cognitive proximity consists of two components: base knowledge and domain expertise. It was observed that companies that shared significant base knowledge communicated more effectively on technological issues and thus had a greater chance at successfully transferring knowledge. Conversely, companies with substantially different base knowledge would likely find it more difficult to communicate and transfer knowledge. There is a paradoxical dual impact of 'cognitive gaps' - disrupting effective communication and collaboration while simultaneously ensuring diversity necessary for strong, robust solutions. The three M\&A cases examined corroborate that it is not knowledge alone that matters; differences between the cognitive abilities and approaches matter.

In terms of innovation, it is observed that companies with very little distinct domain expertise were only successful in producing incremental innovations. In addition, the termination of projects, product lines and people tend to elevate difficulties in knowledge preservation; knowledge resides in people and their departure results in a loss of knowledge and expertise (Ranft and Lord, 2000). On the other hand, if firms possess different domain expertise, the need to terminate projects, product lines, and people would be less. Also the likelihood for a greater degree of complementarity between the firms' technological capabilities has the potential to produce radical innovation. From an innovative perspective, it is important to have two companies that on the one hand find a common ground in terms of base knowledge, while on the other hand differ sufficiently in their domain expertise.

In terms of organisational proximity, the results show that closer proximity eases knowledge transfer and allows collaborations to happen more naturally and efficiently. Less organisational proximity requires considerable adjustments from both sides. In some instances, differences could be so large that they are difficult to cope with, which in turn could seriously affect knowledge transfer. However, when differences are moderate and manageable, opportunities for learning and adopting best practices could emerge to improve innovative productivity, such as more efficient product development processes. 


\subsection{Limitations and directions for future research and practice}

This study has limitations. Since it is based on qualitative analysis of three cases, the findings offer limited possibility of generalising to a broad population. However, the strength of case study research lies in its ability to provide in-depth analysis of qualitative data that can be used to extend existing theories or build new theories (Creswell, 2007; Eisenhardt, 1989; Miles and Huberman, 1994). The findings from this study help extend existing theory. First, the study illuminates the relationship between various dimensions of proximity and M\&A knowledge transfer, which has not attracted sufficient research attention. In the current literature, the main focus has been on geographic proximity in relation to knowledge transfer between organisations (Ambos and Ambos, 2009; Jasimuddin, 2007) and within organisations (Zander and Kogut, 1995). Much less attention has been paid to knowledge transfer in the M\&A context. This study has demonstrated the role that other proximity dimensions and management interventions play in technology-based M\&A.

Second, the present study provides a new perspective to view cognitive proximity. Unlike the current literature that measures proximity mainly based on how close firms are technologically, the present study sheds light on the distinction between base knowledge and domain expertise. The findings suggest that similarity in base knowledge enables firms to communicate and absorb each other's knowledge while dissimilarity in domain expertise creates chances to explore new technological opportunities. Measuring cognitive proximity at these two levels of knowledge would likely allow for a better assessment of the suitability between M\&A partners in terms of cognitive proximity and provide better predictability of post-M\&A innovative performance. In addition, the study reveals the complexity of organisational proximity in technology M\&A, where there are both positive and negative impacts of organisational factors on knowledge transfer that would affect the innovative outcome. The qualitative method employed in this study provides a basis to help explain why strong innovative performance occurs and why it does not; a finding that is not well articulated in the extant literature.

From a managerial perspective, this study presents two main findings which warrant consideration when executives embark on the M\&A path. First, the findings on the relationships between proximity and knowledge transfer and innovation could assist practitioners to better select and evaluate potential M\&A targets. They would be able to better assess the proximity dimensions between the acquirer and the potential target in finding an optimally suitable candidate. This would reduce costly strategic errors of merging with or acquiring an 'unfit' partner. Second, the findings could improve managerial practices for post-M\&A integration, knowledge transfer, and innovation. For instance, if incremental innovations are sought, then both the acquiring and acquired firms should have a strong base of overlapping knowledge, and if the goal is to generate radical innovation, then some level of base knowledge combined with differences in domain expertise are required.

\section{Acknowledgements}

The authors would like to thank the Social Sciences and Humanities Research Council of Canada for funding this research through grants \# 410-2004-0049, \# 410-2005-0262, and \# 604-2007-0004 as well as the Telfer School of Management Research Fund. 


\section{References}

Ahuja, G. and Katila, R. (2001) 'Technological acquisitions and the innovation performance of acquiring firms: a longitudinal study', Strategic Management Journal, Vol. 22, No. 3, pp.197-220.

Ambos, T.C. and Ambos, B. (2009) 'The impact of distance on knowledge transfer effectiveness in multinational corporations', Journal of International Management, Vol. 15, No. 1, pp.1-14.

Arrow, K.J. (1969) 'Classificatory notes on the production and transmission of technological knowledge', American Economic Review, Vol. 59, No. 2, pp.29-35.

Bannert, V. and Tschirky, H. (2004) 'Integration planning for technology intensive acquisitions', $R \& D$ Management, Vol. 34, No. 5, pp.481-494.

Barkema, H. and Vermeulen, F. (1998) 'International expansion through start-up or acquisition: a learning perspective', Academy Management Journal, Vol. 41, No. 1, pp.7-26.

Barrett, A. (2002) 'Johnson \& Johnson: a shopping spree waiting to happen', Businessweek, 17 June.

Berends, H., Garud, R., Debackere, K. and Weggeman, M. (2011) 'Thinking along: a process for tapping into knowledge across boundaries', International Journal of Technology Management, Vol. 53, No. 1, pp.69-88.

Blanc, H. and Sierra, C. (1999) 'The internationalization of R\&D by multinationals: a trade-off between external and internal proximity', Cambridge Journal of Economics, Vol. 23, No. 2, pp.187-206.

Boschma, R.A. (2005) 'Proximity and innovation: a critical assessment', Regional Studies, Vol. 39, No. 1, pp.61-74.

Brannen, M.Y. and Peterson, M.F. (2009) 'Merging without alienating: interventions promoting cross-cultural organizational integration and their limitations', Journal of International Business Studies, Vol. 40, No. 3, pp.468-489.

Breschi, S., Lissoni, F. and Malerba, M. (2003) 'Knowledge-relatedness in firm technological diversification', Research Policy, Vol. 32, No. 1, pp.69-87.

Cairncross, F. (1997) The Death of Distance, Harvard Business School Press, Cambridge, MA.

Calderini, M. and Garrone, P. (2003) 'Mergers and acquisitions and innovation strategies', in Calderini, M., Garrone, P. and Sobrero, M. (Eds.): Corporate Governance, Market Structure and Innovation, Edward Edgar, UK.

Cantwell, J. and Zhang, Y. (2011) 'Innovation and location in the multinational firm', International Journal of Technology Management, Vol. 54, No. 1, pp.116-132.

Capron, L. (1999) 'The long-term performance of horizontal acquisitions', Strategic Management Journal, Vol. 20, No. 11, pp.987-1018.

Chaudhuri, S. (2004) Can Innovation Be Bought? Managing Acquisitions in Dynamic Environments, Unpublished $\mathrm{PhD}$ dissertation, Harvard University.

Chen, W.Y., Hsu, B.F., Wang, M-L. and Lin, Y-Y. (2011) 'Fostering knowledge sharing through human resource management in R\&D teams', International Journal of Technology Management, Vol. 53, Nos. 2/3/4, pp.309-330.

Cloodt, M., Hagedoorn, J. and Kranenburg, H.V. (2006) 'Mergers and acquisitions: their effect on the innovative performance of companies in high-tech industries', Research Policy, Vol. 35, No. 5, pp.642-654.

Cohen, W.M. and Levinthal, D.A. (1990) 'Absorptive capacity: a new perspective on learning and innovation', Administrative Science Quarterly, Vol. 35, No. 1, pp.128-152.

Coles, A.M., Harris, L. and Dickson, K. (2003) 'Testing goodwill: conflict and cooperation in new product development', International Journal of Technology Management, Vol. 25, Nos. 1/2, pp.51-64.

Creswell, J.W. (2007) Qualitative Inquiry and Research Design: Choosing among Five Approaches, 2nd ed., Sage Publications, Thousand Oaks, CA.

Datta, D.K. (1991) 'Organizational fit and acquisition performance: effects of post-acquisition integration’, Strategic Management Journal, Vol. 12, No. 4, pp.281-297. 
Desrochers, P. (2001) 'Geographical proximity and the transmission of tacit knowledge', Review of Austrian Economics, Vol. 14, No. 1, pp.25-46.

Dickson, K. (1996) 'How informal can you be? Trust and reciprocity within co-operative and collaborative relationships', International Journal of Technology Management, Vol. 11, Nos. 1/2, pp.129-139.

Eisenhardt, K.M. (1989) 'Building theories from case study research', Academy of Management Review, Vol. 14, No. 4, pp.532-550.

Eisenhardt, K.M. (1991) 'Better stories and better constructs: the case for rigor and comparative logic', Academy of Management Review, Vol. 16, No. 3, pp.620-627.

Eisenhardt, K.M. and Graebner, M.E. (2007) 'Theory building from cases: opportunities and challenges', Academy of Management Journal, Vol. 50, No. 1, pp.25-32.

Ensign, P.C. (1999) 'Innovation in the multinational firm with globally dispersed R\&D: technological knowledge utilization and accumulation', Journal of High Technology Management Research, Vol. 10, No. 2, pp.203-221.

Ensign, P.C. (2009) Knowledge Sharing among Scientists, Palgrave Macmillan, New York, NY.

Ferrary, M. (2003) 'Managing the disruptive technologies life cycle by externalizing the research: social network and corporate venturing in the Silicon Valley', International Journal of Technology Management, Vol. 25, Nos. 1/2, pp.165-180.

Graebner, M.E. (2004) 'Momentum and serendipity: how acquired leaders create value in the integration of technology firms', Strategic Management Journal, Vol. 25, Nos. 8/9, pp.751-777.

Graebner, M.E., Eisenhardt, K.M. and Roundy, P.T. (2010) 'Success and failure in technology acquisitions: lessons for buyers and sellers', Academy of Management Perspectives, Vol. 24, No. 3, pp.73-92.

Hacklin, F., Marxt, C. and Fahrni, F. (2010) 'An evolutionary perspective on convergence: inducing a stage model of inter-industry innovation', International Journal of Technology Management, Vol. 49, Nos. 1/2/3, pp.220-249.

Hagedoorn, J. and Duysters, G. (2000) The Effect of Mergers and Acquisitions on the Technological Performance of Companies in a High-tech Environment, ECIS Working Papers 00.04, Eindhoven Centre for Innovation Studies, Eindhoven University of Technology.

Haspeslagh, P.C. and Jemison, D.B. (1991) Managing Acquisitions: Creating Value Through Corporate Renewal, Free Press, New York.

Hitt, M.A., Hoskisson, R.E., Ireland, R.D. and Harrison, J.S. (1991) 'Effects of acquisitions on R\&D inputs and outputs', Academy of Management Journal, Vol. 34, No. 3, pp.693-706.

Iansiti, M. (1995) 'Technology integration: Managing technological evolution in a complex environment', Research Policy, Vol. 24, No. 4, pp.521-542.

James, A., Georghiou, L. and Metcalfe, J.S. (1998) 'Integrating technology into merger and acquisition decision making', Technovation, Vol. 8, Nos. 8/9, pp.563-573.

Jasimuddin, S.M. (2007) 'Exploring knowledge transfer mechanisms: the case of a UK-based group within a high-tech global corporation', International Journal of Information Management, Vol. 27, No. 4, pp.294-300.

Jemison, D.B. and Sitkin, S.B. (1986) 'Corporate acquisitions: a process perspective', Academy of Management Review, Vol. 11, No. 1, pp.145-163.

Jensen, M. (1988) 'Takeovers: their causes and consequences', Journal of Economic Perspectives, Vol. 2, No. 1, pp.21-48.

King, D.R., Dalton, D.R., Daily, C.M. and Covin, J.G. (2004) 'Meta-analyses of post-acquisition performance: indications of unidentified moderators', Strategic Management Journal, Vol. 25, No. 2, pp.187-200.

Kuznets, S. (1966) Modern Economic Growth: Rate, Structure, and Spread, Yale University Press, New Haven, CT. 
Laamanen, T. and Autio, E. (1996) 'Dominant dynamic complementarities and technologymotivated acquisitions of new, technology-based firms', International Journal of Technology Management, Vol. 12, Nos. 7/8, pp.769-786.

Leifer, R., McDermott, C.M., O'Connor, G.C., Peters, L.S., Rice, M. and Veryzer Jr., R.W. (2000) Radical Innovation: How Mature Companies Can Outsmart Upstarts, Harvard Business School Press, Boston, Massachusetts, USA.

Lubatkin, M.H. (1983) 'Mergers and the performance of the acquiring firm', Academy of Management Review, Vol. 8, No. 2, pp.218-225.

Makri, M., Hitt, M.A. and Lane, P.J. (2010) 'Complementary technologies, knowledge relatedness, and invention outcomes in high technology mergers and acquisitions', Strategic Management Journal, Vol. 31, No. 6, pp.602-628.

Man, A.P. and Duysters, G. (2005) 'Collaboration and innovation: a review of the effects of mergers, acquisitions and alliances on innovation', Technovation, Vol. 25, No. 5, pp.1377-1387.

Miles, M.B. and Huberman, A.M. (1994) Qualitative Data Analysis, 2nd ed., Sage, Thousand Oaks, CA.

Patton, M.Q. (2002) Qualitative Research and Evaluation Methods, 3rd ed., Sage, Thousand Oaks, CA.

Perez, C. and Soete, L. (1988) 'Catching up in technology: entry barriers and windows of opportunity', in Dosi, G., Freeman, C., Nelson, R. and Soete, L. (Eds.): Technical Change and Economic Theory, Pinter, London, UK.

Prabhu, J.C., Chandy, R.K. and Ellis, M.E. (2005) 'The impact of acquisitions on innovation: poison pill, placebo, or tonic?', Journal of Marketing, Vol. 69, No. 1, pp.114-130.

Puranam, P. and Srikanth, K. (2007) 'What they know vs. what they do: how acquirers leverage technology acquisitions', Strategic Management Journal, Vol. 28, No. 8, pp.805-825.

Quintana, C. and Benavides, C.A. (2010) 'Accessing technological knowledge through R\&D alliances: consequences for radical and incremental innovation', DRUID - Danish Research Unit for Industrial Dynamics, Conference Proceedings.

Rallet, A. and Torre, A. (1999) 'Is geographical proximity necessary in the innovation networks in the era of global economy?', GeoJournal, Vol. 49, No. 4, pp.373-380.

Ranft, A. (2006) 'Knowledge preservation and transfer during post-acquisition integration', in Finkelstein, S. and Cooper, C. (Ed.): Advances in Mergers \& Acquisitions, pp.51-67, Emerald Group Publishing, Bingley, UK.

Ranft, A. and Lord, M.D. (2000) 'Acquiring new knowledge: the role of retaining human capital in acquisitions of high-tech firms', Journal of High Technology Management Research, Vol. 11, No. 2, pp.295-319.

Ranft, A. and Lord, M.D. (2002) 'Acquiring new technologies and capabilities: a grounded model for acquisition implementation', Organization Science, Vol. 13, No. 4, pp.420-441.

Saxenian, A.L. (1994) Regional Advantage: Culture and Competition in Silicon Valley and Route 128, Harvard University Press, Cambridge, MA.

Schweizer, L. (2005) 'Organizational integration of acquired biotechnology companies in pharmaceutical companies: the need for a hybrid approach', Academy of Management Journal, Vol. 48, No. 6, pp.1051-1074.

Tellis, W. (1997) 'Application of a case study methodology', The Qualitative Report, Vol. 3, No. 2, pp.1-19.

Vermeulen, F. and Barkema, H. (2001) 'Learning through acquisitions', Academy of Management Journal, Vol. 44, No. 3, pp.457-476.

Yin, R. (2009) Case Study Research: Design and Methods, 4th ed., Sage Publishing, Thousand Oaks, CA.

Zander, U. and Kogut, B. (1995) 'Knowledge and the speed of the transfer and imitation of organizational capabilities', Organization Science, Vol. 6, No. 1, pp.76-92. 


\section{Notes}

1 Usually in a merger, one party is more dominant than the other (Haspeslagh and Jemison, 1991), and this was true in the case of MajCom/NextCom.

2 We note that measures of success tend to be complex and multiple. In this paper, we focused mainly on innovation, but we acknowledge that other measures of success can also be adopted. For example, MajCom/Next Com started off with a cost-cutting strategy and was successful with it, while the side effects of knowledge transfer were only somewhat successful. Thus, the initial intention behind the M\&A helps drive its outcomes. We are thankful to Reviewer B for this observation. 